\title{
Comparison of Endoscopic Endonasal Reduction and Transcaruncular Reduction for the Treatment of Medial Orbital Wall Fractures
}

\section{Summary}

Background: Currently, endoscopic endonasal reduction and transcaruncular reduction are frequently used as surgical treatments for medial orbital wall fractures. However, these two surgical techniques have not been comprehensively compared using objective criteria. Therefore, the results of these two techniques were compared retrospectively using eight objective criteria in patients with medial orbital wall fracture.

Methods: This study included 48 medial orbital wall fracture patients treated from June 1993 to July 2006: 29 had endoscopic endonasal reduction, and 19 had transcaruncular reduction. Computed tomographic scans, double vision field testing for diplopia using Goldmann perimetry, and Hertel's exophthalmometer were done pre- and post-surgery.

Results: The average follow-up period was 70.8 months. Among patients with pure medial orbital wall fractures, the average reduction rate was $89.2 \%$ for the endoscopic endonasal reduction group and $90.7 \%$ for the transcaruncular reduction group. One case in the endoscopic endonasal reduction group had a more than $2 \mathrm{~mm}$ enophthalmos after surgery. The diplopia correction rate was $1.8 \%$ in the endoscopic endonasal reduction group and $2.7 \%$ in the transcaruncular reduction group. None of the above differences were statistically significant. However, among patients with pure medial orbital wall fractures, compared to the trancaruncular reduction group, the average operation time, the average hospital stay, and the average cost were significantly greater in the endoscopic endonasal reduction group.

Conclusions: The two surgical methods had a similar effectiveness; however, transcaruncular reduction appeared to be more advantageous with respect to the operation time, the length of hospital stay and cost.

\section{BACKGROUND}

Medial orbital wall fractures occur in the most fragile area, the lamina papyracea, and are caused by blunt periorbital trauma. ${ }^{1}$

In contrast to inferior orbital wall fractures, the clinical symptoms of medial orbital wall fractures are minor, even in cases with displacement. Thus, medial orbital wall fractures may be left ignored and untreated. In fact, while the incidence of these fractures is high, the diagnostic rate is low. Since these fractures are associated with large defects, medial 
orbital wall fractures can cause late enophthalmos. If surgery is not performed at the appropriate time, noticeable enophthalmos can develop. Hence, aggressive diagnosis and surgical correction are desirable for medial orbital wall fracture patients. ${ }^{1}$

To surgically treat medial orbital wall fractures, one needs to reach the medial orbital wall; various approaches using different paths have been reported. Recently, the endoscopic endonasal approach and the transcaruncular approach have been reported frequently. Previous reports simply described the advantages and disadvantages of the approaches and their results; these two surgical approaches have not yet been compared comprehensively and objectively based on specific criteria. ${ }^{2-11}$

Therefore, in patients with a reduction of a medial orbital wall fracture by either the endoscopic endonasal approach or the transcaruncular approach, we retrospectively compared the two approaches' surgical outcomes objectively with respect to the reduction rate, the degree of enophthalmos, the diplopia correction rate, extraocular movement limitation, operation time, hospital stay, cost, and complications.

\section{PATIENTS and METHODS}

\section{Subjects}

The study included 48 medial orbital wall fracture patients (34 males, 14 females; mean age, 34 years; age range, 11 to 63 years) seen at our hospital from June 1993 to July 2006. Endoscopic endonasal reduction was done in 29 cases, and transcaruncular reduction was done in 19 cases. The procedure was selected randomly. Only one expert plastic surgeon (TH Choi) have operated transcaruncular reduction and one expert rhinologist (SY Jeon) have operated endoscopic endonasal reduction. The fractures were caused by violence in 24 cases, traffic accidents in 15 cases, and falls in 9 cases. Twenty-seven patients had pure medial orbital wall fractures, while 21 patients had more than one concomitant fracture in another facial area. Concomitant fractures included inferior orbital wall fracture in 10 patients, nasal bone fracture in 7 patients, zygomatic bone fracture in 6 patients, frontal bone fracture in 1 patient, and a Le Fort I fracture in 1 patient. The interval from the time of injury to being seen at our hospital ranged from 1 to 57 days (average, 12 days) (Tables 1, 2).

The patients were diagnosed based on the results of physical examination, plain radiographs, and computed tomographic (CT) scans. Presurgically, approximately 5 - 7 days after the injury, when the edema had completely subsided, double vision field testing for diplopia using Goldmann perimetry was performed, and the degree of enophthalmos was measured using Hertel's exophthalmometer. At the time of the final 
follow-up visit after surgery, the same examinations were repeated. The patients who had endoscopic endonasal reduction had immediate CT scans 1 day after surgery to assess the degree of reduction.

Surgery was done in patients who had one of four clinical symptoms, such as extraocular movement limitation, diplopia, and enophthalmos of more than $2 \mathrm{~mm}$, and in patients with medial orbital wall fractures that were greater than $2 \mathrm{~cm}^{2}$ in area on CT scan.

\section{Evaluation methods}

The following eight parameters for all patients were used to evaluate and compare the two approaches. In addition, to compare more accurately, the patients with a pure medial orbital wall fracture only (17 of these had endoscopic endonasal reduction, and 10 had transcaruncular reduction) were compared separately.

\section{a. Reduction rate}

The volume of the herniated orbital tissues was obtained based on the CT scan. The areas with a displaced fracture or herniated soft tissues were measured in all sections; the results were added together and multiplied by the section thickness to obtain the volume (Fig. 1). The reduction rate was obtained by subtracting the postsurgical volume from the presurgical volume, dividing by the presurgical volume, and then multiplying by 100 .

Reduction rate $(\%)=($ presurgical volume - postsurgical volume $) /$ presurgical volume X 100

\section{b. Enophthalmos}

The number of patients with more than $2 \mathrm{~mm}$ presurgical enophthalmos and with more than $2 \mathrm{~mm}$ enophthalmos after surgery was compared.

\section{c. Diplopia correction rate}

The degree of diplopia improvement was compared using the Binocular Single Vision score (BSV score). The BSV score was introduced by Woodruff et al.; in patients with diplopia, it assesses the functional aspects of diplopia by assigning a number that allows the severity of diplopia, the degree of progression of diplopia, and specific extraocular movement limitation to be objectively compared. 
The patient's BSV field was plotted using the Goldmann Perimeter. After the BSV field was plotted, a transparent scoring template (Fig. 2) was used to calculate the BSV score. The scoring template consists of a transparent sheet divided into 55 segments. The total value for all 55 segments is 124 . The template is placed over the plotted chart, and all segments overlying the nondiplopic areas are scored. The patient's score is added and calculated as a percentage of the normal full field of BSV. ${ }^{12,13}$

$$
\text { BSV score }(\%)=(\text { the sum of nondiplopic areas scores }) / 124 \text { X } 100
$$

The diplopia correction rate was obtained by subtracting the presurgical BSV score (\%) from the postsurgical BSV score (\%).

\section{d. Extraocular movement limitation}

The number of patients with extraocular movement limitation prior to surgery and the number of patients with persistent extraocular movement limitation after surgery were compared.

\section{e. Operation time}

The total operation time was compared.

\section{f. Hospital stay}

The total length of hospital stay was compared.

\section{g. Cost}

The total cost and patient share were compared.

\section{h. Complications}

The number of patients was compared with respect to complications, including retrobulbar hemorrhage, optic nerve injury, implant displacement, protrusion, and infection.

\section{Surgical technique}

\section{a. Endoscopic endonasal reduction}

Microsurgical endonasal reconstruction of the medial orbital wall fractures was done under general anesthesia. All procedures were done under the operating microscope. The middle meatus was opened using a long Killian speculum. The uncinate process 
was resected with a knife; the bulla and ethmoidal air cells were resected using forceps. The fractured bones of the lamina papyracea and the herniated orbital contents were identified behind the resected air cells. The fractured lamina papyracea was removed. The orbital contents were separated from the air cell mucosa and pushed back laterally with the long blade of a Killian speculum. The ethmoidectomy was completed, and a thin U-shaped Silastic ${ }^{\circledR}$ sheet (0.020 inches thick) was inserted to cover the lamina papyracea and the ethmoidectomy cavity. The size of the Silastic ${ }^{\circledR}$ sheet was individually tailored to avoid disturbing ostial drainage of the frontal and maxillary sinuses. Merocel ${ }^{\circledR}$ packing was placed and soaked with a broad spectrum antibiotic solution. The shape of the medial orbital wall was fixed by the Silastic ${ }^{\circledR}$ sheet and the Merocel ${ }^{\circledR}$ packing. After hospitalization for 2 weeks, the patients were followed-up weekly in the outpatient clinic. Three or four weeks after surgery, the Merocel ${ }^{\circledR}$ packing and the Silastic ${ }^{\circledR}$ sheet were removed under topical anesthesia.

\section{b. Transcaruncular reduction}

Under general anesthesia, 1\% lidocaine with 1:100,000 epinephrine was injected in the medial bulbar conjunctiva and caruncle. A small conjunctival incision was made through the caruncle using Wescott scissors. The incision was extended by cutting the conjunctiva superiorly and inferiorly into the fornices, for a distance of approximately $15 \mathrm{~mm}$. Stevens scissors were used to bluntly dissect in the anteroposterior direction to the posterior lacrimal crest. Using the malleable retractors, the orbital soft tissue was retracted, and a further dissection was carried out until the posterior lacrimal crest was felt through the tip of the scissors. Once the posterior lacrimal crest was identified, the periosteum of the medial wall was exposed. A \#15 blade was used to incise the periosteum of the medial wall just posterior to the posterior lacrimal crest. A Freer elevator was used to dissect the periorbita posteriorly until the margin of the fracture was clearly seen. If necessary, the anterior and posterior ethmoidal vessels were identified and cauterized by dissecting further. Herniated orbital tissue was retracted using a malleable retractor and a Freer elevator. To confirm the complete release of the orbital tissues, a force duction test was performed. The fracture size was then measured. The fracture was reconstructed using the suitable size of Medpor ${ }^{\circledR}$. The conjunctiva was closed using 6-0 plain gut sutures.

\section{Results}

The follow-up period ranged from 11 to 163 months, with an average of 70.8 months. 


\section{Reduction rate}

Twelve patients who had endoscopic endonasal reduction and thirteen patients who had transcaruncular reduction completed long-term follow-up and were compared. The average postsurgical reduction rate was determined based on the CT scans; it was $80.9 \%$ with endoscopic endonasal reduction and $88.8 \%$ with transcaruncular reduction. The difference between the groups was not statistically significant (Mann-Whitney test, $p=$ 0.313). Among the patients who had pure medial orbital wall fractures only, the average postsurgical reduction rate was $89.2 \%$ with endoscopic endonasal reduction and $90.7 \%$ with transcaruncular reduction. The difference between the groups was also not statistically significant (Mann-Whitney test, $p=0.566$ ) (Table 3).

\section{Enophthalmos}

Compared to pre-surgery, the degree of enophthalmos improved post-surgery in most cases. However, four endoscopic endonasal reduction cases (patients 3, 19, 22, and 25) and two transcaruncular reduction cases (patients 16 and 18) continued to have more than $2 \mathrm{~mm}$ enophthalmos post-surgery. The difference between the groups was not statistically significant (Chi-Square test, $p=0.738$ ). Among the patients who had pure medial orbital wall fractures only, one endoscopic endonasal reduction cases (patients 3) continued to have more than $2 \mathrm{~mm}$ enophthalmos post-surgery. The difference between the groups was also not statistically significant (Chi-Square test, $p=0.434$ ) (Table 4).

\section{Diplopia correction rate}

Eight patients who had endoscopic endonasal reduction and ten patients who had transcaruncular reduction completed long-term follow-up and were compared. The BSV score (\%) improved by an average of 3.8\% in the endoscopic endonasal reduction group and by an average of $14.7 \%$ in the transcaruncular reduction group (Mann-Whitney test, $p=0.534)$; thus, the difference between the groups was not statistically significant. Among the patients who had pure medial orbital wall fractures only, the BSV score (\%) improved by an average of $1.8 \%$ in the endoscopic endonasal reduction group and by an average of $2.7 \%$ in the transcaruncular reduction group (Mann-Whitney test, $p=0.754$ ); thus, the difference between the groups was also not statistically significant (Table 3).

\section{Extraocular movement limitation}


Extraocular movement limitation was not present in any of the 48 cases before surgery, and none of the patients developed extraocular movement limitation after surgery (Table 4).

\section{Operation time}

The average operation time was significantly longer in the endoscopic endonasal reduction group (159.2 minutes) than in the transcaruncular reduction group (106.4 minutes; Mann-Whitney test, $p=0.018$ ). Among the patients who had pure medial orbital wall fractures only, the average operation time was significantly longer in the endoscopic endonasal reduction group (132.9 minutes) than in the transcaruncular reduction group (81.6 minutes; Mann-Whitney test, $p<0.001$ ) (Table 4).

\section{Hospital stay}

The average hospital stay was 21.8 days in the endoscopic endonasal reduction group and 21 days in the transcaruncular reduction group (Mann-Whitney test, $p=0.390$ ); the difference between the groups was not statistically significant. Among the patients who had pure medial orbital wall fractures only, the average hospital stay was significantly longer in the endoscopic endonasal reduction group (21.5 days) than in the transcaruncular reduction group (14.9 days; Mann-Whitney test, $p=0.021$ ) (Table 4).

\section{Cost}

The average cost of endoscopic endonasal reduction was 5,099 US dollars in total cost and 1,791 US dollars in patient share, while that of transcaruncular reduction was 3,642 US dollars in total cost and 1,209 US dollars in patient share; these differences were statistically significant (Mann-Whitney test, $p<0.001$ ). Among the patients who had pure medial orbital wall fracture only, the average cost of endoscopic endonasal reduction was 4,594 US dollars in total cost and 1,638 US dollars in patient share, while that of transcaruncular reduction was 3,609 US dollars in total cost and 1,180 US dollars in patient share; these differences were also statistically significant (MannWhitney test, $p<0.001$ ) (Table 4).

\section{Complications}

No patients developed retrobulbar hemorrhage, optic nerve injury, implant infections, or other complications. However, in one transcaruncular reduction case (patient 8), the implant became displaced, and re-operation was required to reposition the implant. The difference between the groups was not statistically significant (Chi-Square test, $p=$ 
0.212). Among the patients who had pure medial orbital wall fractures only, the difference between the groups was also not statistically significant (Chi-Square test, $p=$ 0.184) (Table 4).

\section{Discussion}

Currently, endoscopic endonasal reduction and transcaruncular reduction are frequently used surgical approaches for treating medial orbital wall fracture patients. According to previous studies, these two approaches have several advantages and disadvantages.

Endoscopic endonasal reduction, in contrast to previous methods such as a subciliary incision, a transconjunctival incision, an upper eyelid incision, a direct medial canthal incision, and a bicoronal incision, has the advantages that: it does not leave a scar; it does not use an inorganic implant and autogenous material, so that there is no possibility of protrusion or herniation; the surgery can be performed under local anesthesia, which means that extraocular movement testing can be performed during surgery; the hospital stay is short; and the surgeon's surgical view is excellent. However, the operation time is long, the Silastic sheet ${ }^{\circledR}$ is large, which prevents the release of secretions from the frontal and maxillary sinuses and, thus, may induce sinusitis, and, in cases with cerebrospinal fluid leakage and concomitant facial fractures in other facial areas, endoscopic endonasal reduction is technically not easy. In addition, a second procedure is required to remove the packing materials..$^{2-4,8-10}$

On the other hand, the advantages of transcaruncular reduction include: it is safe, and the operation time is short; there is no scar after surgery; in contrast to endoscopic endonasal reduction, ethmoid structures are not removed, so that the forces supporting the lamina papyracea are not weakened over time; and a second procedure is not required. The disadvantages of transcaruncular reduction include that: it can only be performed under general anesthesia; implants cannot be inserted deeply to the posterior edge of the fornix; and implant displacement, protrusion, absorption, and infection may occur. $^{2-11}$

Thus, according to previous reports, since both surgical approaches have advantages and disadvantages, it is not possible to determine which is superior. Previous studies have not directly compared the results of these two approaches using comprehensive and objective criteria. Therefore, to compare these two surgical techniques objectively, the following evaluation criteria were defined: the reduction rate as assessed by CT scan, the degree of enophthalmos, the diplopia correction rate as assessed using the BSV 
score (\%), extraocular movement limitation, operation time, length of hospital stay, cost, and the development of complications.

Based on our results, there were no significant differences between the approaches in the reduction rate, the degree of enophthalmos, and the diplopia correction rate. This suggests, that, with respect to the reduction of herniated soft tissues or the reduction of entrapped extraocular muscles, these two approaches were not very different. The reason for this may be that the two approaches advantages and disadvantages balance out. In other words, although endoscopic endonasal reduction offers direct surgical access to the fracture site, in patients with a large defect, permanent implants are not placed. On the other hand, transcaruncular reduction allows a permanent implant to be placed; however, in patients who have a deep defect, it is difficult to insert implants up to the posterior edge of the fracture. ${ }^{7,8,11}$

There was a statistically significant difference in operating times between the two procedures; among patients with pure medial orbital wall fractures, the average operation time was 132.9 minutes for endoscopic endonasal reduction and 81.6 minutes for transcaruncular reduction. The longer operation time for endoscopic endonasal reduction may be due to the hazard posed by the proximity of the orbital contents, the nasolacrimal duct, and the cranial vault. In addition, during endoscopic endonasal reduction, ethmoid air cells can be fragmented and lining mucosa inflamed due to internal hemorrhage; bleeding in the surgical field is common. ${ }^{14}$ Therefore, only experienced endonasal surgeons can perform the surgery safely and skillfully.

Among patients with a pure medial orbital wall fracture, there was a statistically significant difference in the length of hospital stay; the average hospital stay was 21.5 days for endoscopic endonasal reduction and 14.9 days for transcaruncular reduction. Since endoscopic endonasal reduction does not insert intraocular inorganic implants, the packing of Silastic ${ }^{\circledR}$ sheet and Merocel ${ }^{\circledR}$ through the nose is required to maintain the reduction state for 3-4 weeks. During that time, due to the proximity to the cranial vault, there is a risk of ascending infection; thus, patients remain in hospital for 14 days after surgery and receive intravenous antibiotics. In addition, some patients were discharged only after the Silastic ${ }^{\circledR}$ sheet and Merocel ${ }^{\circledR}$ were removed. Thus, the length of stay was longer for endoscopic endonasal reduction than with transcaruncular reduction.

The costs of treating pure medial orbital wall fractures differed significantly; the average cost of endoscopic endonasal reduction was 4,594 US dollars in total cost and 1,638 US dollars in patient share, while that of transcaruncular reduction was 3,609 US dollars in total cost and 1,180 US dollars in patient share. The difference in cost 
between the procedures is thought to be the result of the cost of general anesthesia and the difference in the length of hospital stay.

Thus, in summary, while both surgical methods were relatively similar in outcomes, transcaruncular reduction was slightly more advantageous due to a shorter operation time, hospital stay, and a lower cost.

In addition, the present report compared the two techniques using objective evaluation criteria, and these evaluation criteria could be used to compare the surgical outcomes of medial orbital wall fractures in the future. In particular, it is thought that the reduction rate criterion could be used as an objective measure of the degree of reduction of herniated tissues in patients with medial orbital wall fractures. To the best of our knowledge, no previous studies have compared and evaluated the degree of reduction using this criterion; in most previous reports, the degree of reduction was simply described as the 'reconstructed orbital wall has a proper position'. 8, 11

In addition, the BSV score (\%) was used for the first time in the present study to evaluate the diplopia correction rate in medial orbital wall fractures. Reviewing several previous reports, based on only 30 or 45 degrees of gaze, the patients' status was simply classified as 'good', indicating no double vision or diplopia of more than 30 or 45 degrees, and 'poor', diplopia of less than 30 or 45 degrees. In the present study, the degree of diplopia correction was accurately assessed using the BSV score (\%). ${ }^{4,10,12}$ Therefore, using the BSV score (\%), the diplopia correction rate could be evaluated more accurately, and the degree of correction could be more clearly communicated and compared among investigators.

One of our study's limitations was that the CT scans and double vision field tests were not performed during long-term follow-up in some patients. Hence, all patients could not be compared according to all of the evaluation criteria. Therefore, in the future, such data will be collected systematically and continuously for a larger number of patients.

\section{Conclusions}

The outcomes of medial orbital wall fracture patients who had either endoscopic endonasal reduction or transcaruncular reduction were compared using objective criteria, such as the reduction rate, the degree of enophthalmos, the diplopia correction rate, extraocular movement limitation, operation time, hospital stay, cost, and complications. The results showed that the two surgical methods were not very different with respect to the reduction rate, the degree of enophthalmos, the diplopia correction rate, and extraocular movement limitation. However, with respect to the operation time, the 
length of hospital stay and cost, transcaruncular reduction was found to be slightly more advantageous than endoscopic endonasal reduction. The reduction rate and the diplopia correction rate, which were used as evaluation criteria for the first time in this study, could be used to evaluate the surgical outcomes of medial orbital wall fracture patients.

\section{Acknowledgements}

This work was supported by the Korea Science and Engineering Foundation (KOSEF) grant funded by the Korea government (MOST) (No. R01-2007-000-20746-0).

\section{References}

1. Burm JS, Chung $\mathrm{CH}$, and Oh SJ. Pure orbital blowout fracture: New concepts and importance of medial orbital blowout fracture. Plast Reconstr Surg 1999;103(7):183949.

2. Katowitz JA, Welsh MG, and Bersani TA. Lid crease approach for medial wall fracture repair. Ophthalmic Surg 1987;18(4):288-90.

3. Jeon SY, Kim C, Ma Y, and Hwang E. Microsurgical intranasal reconstruction of isolated blowout fractures of the medial orbital wall. Laryngoscope 1996;106(7):910-3.

4. Jin HR, Shin SO, Choo MJ, and Choi YS. Endonasal endoscopic reduction of blowout fractures of the medial orbital wall. J Oral Maxillofac Surg 2000;58(8):847-51.

5. Baumann A, and Ewers R. Transcaruncular approach for reconstruction of medial orbital wall fracture. Int J Oral Maxillofac Surg 2000;29(4):264-7.

6. Shorr N, Baylis HI, Goldberg RA, and Perry JD. Transcaruncular approach to the medial orbital and orbital apex. Ophthalmology 2000;107(8):1459-63.

7. Lee MJ, Kang YS, Yang JY, Lee DY, Chung YY, and Rohrich RJ. Endoscopic transnasal approach for the treatment of medial orbital blow-out fracture: A technique for controlling the fractured wall with a balloon catheter and merocele. Plast Reconstr Surg 2002;110(2):417-26.

8. Lee HM, Han SK, Chae SW, Hwang SJ, and Lee SH. Endoscopic endonasal reconstruction of blowout fractures of the medial orbital walls. Plast Reconstr Surg 2002;109(3):872-6.

9. Naraghi M, and Kashfi A. Endonasal endoscopic treatment of medial orbital wall fracture via rotational repositioning. Am J Otolaryngol 2002;23(5):312-5. 
10. Sanno T, Tahara S, Nomura T, and Hashikawa K. Endoscopic endonasal reduction for blowout fracture of the medial orbital wall. Plast Reconstr Surg 2003;112(5):122837.

11. Kim SJ, Lew H, Chung SH, Kook KH, Juan Y, and Lee SY. Repair of medial orbital wall fracture: Transcaruncular approach. Orbit 2005;24(1):1-9.

12. Woodruff G, O'Reilly C, and Kraft SP. Functional scoring of the field of binocular single vision in patients with diplopia. Ophthalmology 1987;94(12):1554-61.

13. Fitzsimons R, and White J. Functional scoring of the field of binocular single vision. Ophthalmology 1990;97(1):33-5.

14. May M, Levine HL, Mester SJ, and Schaitkin B. Complications of endoscopic sinus surgery: Analysis of 2108 patients-incidence and prevention. Laryngoscope 1994;104(9):1080-3.

Figure Legends
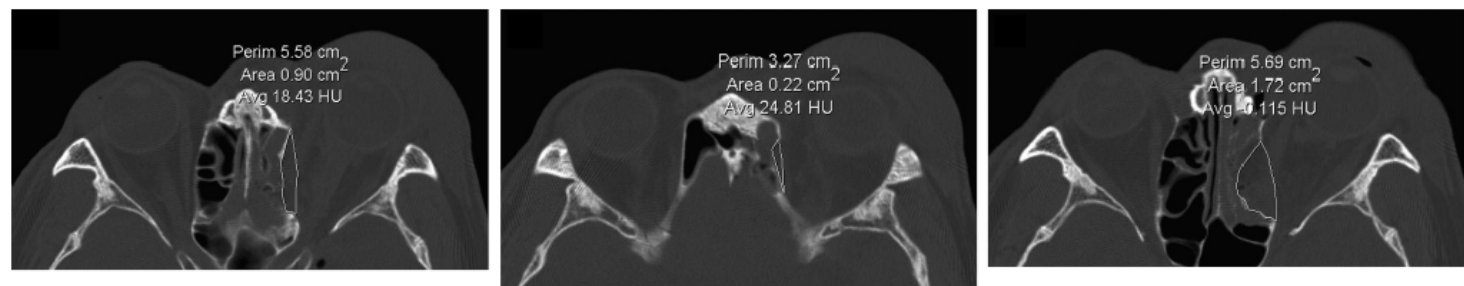

Figure 1. The area of the herniated soft tissues in these three sections is 0.22 (left), 0.90 (center), and 1.72 (right) $\mathrm{cm}^{2}$, respectively. In this patient, the total area of the herniated soft tissues is $9.28 \mathrm{~cm}^{2}$. The section thickness is $0.25 \mathrm{~cm}$. Thus, the total volume is 2.32 $\mathrm{cm}^{3}$.

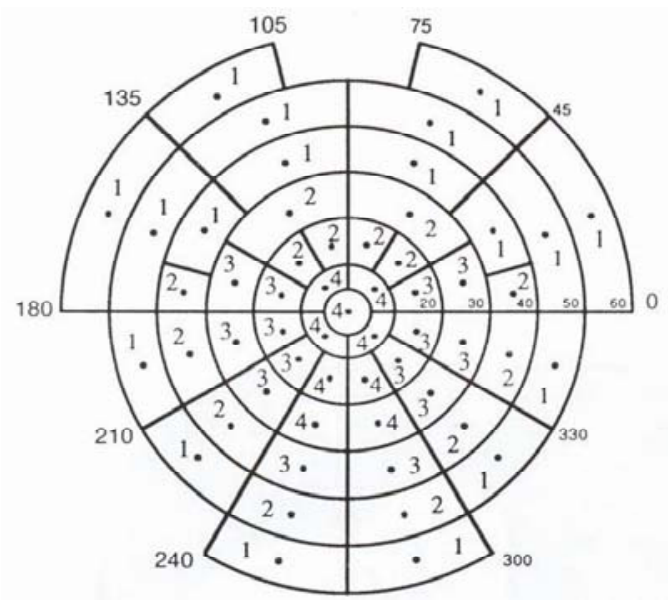

Figure 2. The transparent scoring template. The scoring template consists of a transparent sheet divided into 55 segments. The total value for all 55 segments is 124 . 
Table 1. Summary of 29 Patients Treated with Endoscopic Endonasal Reduction of the Medial Orbital Wall Fracture

\begin{tabular}{|c|c|c|c|c|c|c|c|}
\hline Case No. & $\begin{array}{l}\text { Sex / Age } \\
\text { (years) }\end{array}$ & $\begin{array}{l}\text { Mechanism } \\
\text { of Injury }\end{array}$ & $\begin{array}{l}\text { Associated } \\
\text { Injury }\end{array}$ & $\begin{array}{l}\text { Clinical } \\
\text { Finding }\end{array}$ & $\begin{array}{l}\text { Operation Time } \\
\text { (minutes) }\end{array}$ & $\begin{array}{l}\text { Hospital Stay } \\
\text { (days) }\end{array}$ & $\begin{array}{c}\text { Follow-up } \\
\text { (months) }\end{array}$ \\
\hline 1 & $F / 18$ & Violence & & $E, D$ & 145 & 21 & 163 \\
\hline 2 & $M / 19$ & Violence & & $E, D$ & 130 & 12 & 157 \\
\hline 3 & $M / 25$ & $\mathrm{TA}$ & & $E, D$ & 140 & 60 & 156 \\
\hline 4 & $M / 39$ & Violence & & D & 120 & 34 & 147 \\
\hline 5 & $M / 33$ & $\mathrm{TA}$ & & $E, D$ & 135 & 22 & 143 \\
\hline 6 & $M / 24$ & Violence & & D & 135 & 25 & 133 \\
\hline 7 & $M / 22$ & Violence & & $E, D$ & 140 & 21 & 125 \\
\hline 8 & $M / 38$ & Violence & & $D$ & 120 & 16 & 124 \\
\hline 9 & $M / 17$ & $\mathrm{TA}$ & & $E, D$ & 80 & 20 & 99 \\
\hline 10 & $M / 50$ & Violence & & D & 130 & 18 & 100 \\
\hline 11 & $F / 21$ & $\mathrm{TA}$ & & $E, D$ & 230 & 18 & 50 \\
\hline 12 & $F / 32$ & Fall & & $E, D$ & 140 & 14 & 36 \\
\hline 13 & $M / 38$ & Fall & & $E, D$ & 125 & 22 & 36 \\
\hline 14 & $M / 28$ & Fall & & D & 165 & 20 & 38 \\
\hline 15 & $F / 14$ & Violence & & $D$ & 110 & 10 & 30 \\
\hline 16 & $F / 38$ & Fall & & $E, D$ & 150 & 18 & 26 \\
\hline 17 & $M / 51$ & Violence & & $D$ & 65 & 15 & 24 \\
\hline 18 & $F / 30$ & Fall & Zygoma & $E, D$ & 180 & 16 & 159 \\
\hline 19 & $F / 53$ & TA & Zygoma & $E, D$ & 175 & 33 & 156 \\
\hline 20 & $F / 34$ & Fall & Frontal & $E, D$ & 145 & 23 & 148 \\
\hline 21 & $F / 25$ & Fall & IOW & $E, D$ & 105 & 21 & 139 \\
\hline 22 & $M / 19$ & Violence & IOW, Nasal & $E, D$ & 195 & 27 & 132 \\
\hline 23 & $\mathrm{~F} / 37$ & $\mathrm{TA}$ & Zygoma & $D$ & 160 & 15 & 100 \\
\hline 24 & $M / 42$ & Violence & Le Fort I & $D$ & 220 & 16 & 96 \\
\hline 25 & $M / 36$ & Violence & IOW & $E, D$ & 180 & 15 & 96 \\
\hline 26 & $M / 23$ & Violence & IOW & $E, D$ & 145 & 18 & 40 \\
\hline 27 & M / 35 & $\mathrm{TA}$ & Nasal & $\mathrm{D}$ & 60 & 38 & 38 \\
\hline 28 & $M / 31$ & Violence & Nasal & $E, D$ & 110 & 14 & 38 \\
\hline 29 & $M / 11$ & Violence & IOW & $E, D$ & 120 & 22 & 26 \\
\hline
\end{tabular}

No., number; TA, traffic accident; Zygoma, zygomatic bone fracture; Frontal, frontal bone fracture; IOW, inferior orbital wall fracture;

Nasal, nasal bone fracture; Le Fort I, Le Fort I fracture; E, enophthalmos; D, diplopia. 
Table 2. Summary of 19 Patients Treated with Transcaruncular Reduction of the Medial Orbital Wall Fracture

\begin{tabular}{|c|c|c|c|c|c|c|c|}
\hline Case No. & $\begin{array}{l}\text { Sex / Age } \\
\text { (years) }\end{array}$ & $\begin{array}{l}\text { Mechanism } \\
\text { of Injury }\end{array}$ & $\begin{array}{l}\text { Associated } \\
\text { Injury }\end{array}$ & $\begin{array}{l}\text { Clinical } \\
\text { Finding }\end{array}$ & $\begin{array}{l}\text { Operation Time } \\
\text { (minutes) }\end{array}$ & $\begin{array}{l}\text { Hospital Stay } \\
\text { (days) }\end{array}$ & $\begin{array}{c}\text { Follow-up } \\
\text { (months) }\end{array}$ \\
\hline 1 & $M / 54$ & $\mathrm{TA}$ & & $E, D$ & 50 & 17 & 40 \\
\hline 3 & $M / 24$ & Violence & & $E$ & 55 & 20 & 38 \\
\hline 4 & $M / 48$ & Violence & & $E$ & 60 & 17 & 36 \\
\hline 7 & $F / 30$ & TA & & $E, D$ & 35 & 14 & 26 \\
\hline 8 & $M / 46$ & Violence & & $E, D$ & 60 & 9 & 26 \\
\hline 9 & M / 34 & Violence & & D & 70 & 12 & 24 \\
\hline 10 & $F / 45$ & TA & & $E, D$ & 120 & 17 & 11 \\
\hline 15 & $F / 47$ & $\mathrm{TA}$ & IOW, Nasal & $D$ & 145 & 23 & 39 \\
\hline 16 & $M / 27$ & Fall & IOW & $E, D$ & 100 & 24 & 38 \\
\hline 17 & $M / 63$ & $\mathrm{TA}$ & Nasal & $E, D$ & 125 & 18 & 37 \\
\hline 18 & $M / 36$ & Violence & IOW, Nasal & $E, D$ & 130 & 11 & 36 \\
\hline 19 & $\mathrm{M} / 34$ & TA & IOW & D & 80 & 27 & 28 \\
\hline
\end{tabular}

No., number; TA, traffic accident; Nasal, nasal bone fracture; Zygoma, zygomatic bone fracture; IOW, inferior orbital wall fracture; E, enophthalmos; D, diplopia. 
Table 3. Endoscopic Endonasal Reduction and Transcaruncular Reduction Compared by the Reduction Rate and the Diplopia Correction Rate

\begin{tabular}{|c|c|c|c|c|c|c|c|c|c|c|c|c|c|}
\hline & & \multicolumn{6}{|c|}{ Reduction Rate } & \multicolumn{6}{|c|}{ Diplopia Correction Rate } \\
\hline & & Enc & onasal ( $\mathrm{n}$ & & Transc & uncular ( & $1=13)$ & En & nasal $(n=8$ & & Transc & uncular ( $n=$ & \\
\hline \multicolumn{2}{|c|}{ No. } & $\begin{array}{c}\text { Preop } \\
\text { Volume } \\
\left(\mathrm{cm}^{3}\right)\end{array}$ & $\begin{array}{c}\text { Postop } \\
\text { Volume } \\
\left(\mathrm{cm}^{3}\right)\end{array}$ & $\begin{array}{l}\text { RR } \\
(\%)\end{array}$ & $\begin{array}{c}\text { Preop } \\
\text { Volume } \\
\left(\mathrm{cm}^{3}\right)\end{array}$ & $\begin{array}{c}\text { Postop } \\
\text { Volume } \\
\left(\mathrm{cm}^{3}\right)\end{array}$ & $\begin{array}{l}\text { RR } \\
(\%)\end{array}$ & $\begin{array}{c}\text { Preop } \\
\text { BSV } \\
\text { Score (\%) } \\
\end{array}$ & $\begin{array}{c}\text { Postop } \\
\text { BSV } \\
\text { Score (\%) } \\
\end{array}$ & $\begin{array}{c}\text { DI } \\
(\%)\end{array}$ & $\begin{array}{c}\text { Preop } \\
\text { BSV } \\
\text { Score (\%) } \\
\end{array}$ & $\begin{array}{c}\text { Postop } \\
\text { BSV } \\
\text { Score (\%) } \\
\end{array}$ & $\begin{array}{l}\text { DI } \\
(\%)\end{array}$ \\
\hline \multirow{9}{*}{ Pure } & 1 & 1.36 & 0.15 & 89.0 & 1.03 & 0.08 & 92.2 & 92.7 & 95.1 & 2.4 & 98.3 & 99.1 & 0.8 \\
\hline & 2 & 0.47 & 0.00 & 100 & 0.94 & 0.00 & 100 & 91.9 & 88.7 & -3.2 & 90.3 & 94.3 & 4.0 \\
\hline & 3 & 1.81 & 0.06 & 96.7 & 2.32 & 0.72 & 69.0 & 80.6 & 85.4 & 4.8 & 96.8 & 95.2 & -1.6 \\
\hline & 4 & 1.61 & 0.20 & 87.6 & 1.10 & 0.00 & 100 & 88.7 & 91.9 & 3.2 & 99.2 & 95.2 & -4.0 \\
\hline & 5 & 1.00 & 0.20 & 80.0 & 2.08 & 0.08 & 96.2 & 90.3 & 91.9 & 1.6 & 50.0 & 64.5 & 14.5 \\
\hline & 6 & 1.20 & 0.22 & 81.7 & 1.20 & 0.12 & 90.0 & & & & & & \\
\hline & 7 & & & & 1.60 & 0.20 & 87.5 & & & & & & \\
\hline & Mean & 1.24 & 0.14 & 89.2 & 1.47 & 0.17 & 90.7 & 88.9 & 90.6 & 1.8 & 86.9 & 89.7 & 2.7 \\
\hline & \multicolumn{7}{|c|}{$p=0.566$} & \multicolumn{6}{|c|}{$p=0.754$} \\
\hline \multirow{6}{*}{ Impure } & 1 & 1.80 & 0.00 & 100 & 1.09 & 0.03 & 97.2 & 84.3 & 87.9 & 3.6 & 3.2 & 41.1 & 37.9 \\
\hline & 2 & 1.20 & 0.12 & 90.0 & 2.26 & 0.07 & 96.9 & 10.5 & 21.8 & 11.3 & 7.3 & 7.3 & 0.0 \\
\hline & 3 & 1.37 & 0.15 & 89.1 & 4.24 & 0.66 & 84.4 & 78.2 & 84.7 & 6.5 & 84.6 & 95.1 & 10.5 \\
\hline & 4 & 2.10 & 0.35 & 83.3 & 0.74 & 0.11 & 85.1 & & & & 2.5 & 64.5 & 62.0 \\
\hline & 5 & 1.90 & 0.88 & 53.7 & 3.57 & 0.14 & 96.1 & & & & 61.3 & 83.9 & 22.6 \\
\hline & 6 & 0.83 & 0.67 & 19.3 & 1.01 & 0.40 & 60.4 & & & & & & \\
\hline \multirow{2}{*}{ Total } & Mean & 1.30 & 0.25 & 80.9 & 1.78 & 0.20 & 88.8 & 77.2 & 80.9 & 3.8 & 59.4 & 74.0 & 14.7 \\
\hline & \multicolumn{7}{|c|}{$p=0.313$} & \multicolumn{6}{|c|}{$p=0.534$} \\
\hline
\end{tabular}

Endonasal, endoscopic endonasal reduction; Transcaruncular, transcaruncular reduction; No., number; Preop, preoperative; Postop, postoperative; RR, reduction rate; BSV, binocular single vision; DI, difference; Pure, pure medial orbital wall fracture; Impure, impure medial orbital wall fracture. 
Table 4. Endoscopic Endonasal Reduction and Transcaruncular Reduction Compared by Enophthalmos, Extraocular Movement Limitation, Operation Time, Hospital Stay, Cost, and Complications

\begin{tabular}{llccc}
\hline & & Endonasal & Transcaruncular & $p$ \\
\hline \multirow{2}{*}{ No. of postoperative enophthalmos } & Pure & 1 & 0 & 0.434 \\
No. of postoperative EOM & Total & 4 & 2 & 0.738 \\
Operation time (minutes) & & 0 & 0 & $<0.001 *$ \\
& Pure & 132.9 & 81.6 & $0.018 *$ \\
Hospital stay (days) & Total & 159.2 & 106.4 & $0.021 *$ \\
\multirow{3}{*}{ Cost (total cost, US dollars) } & Pure & 21.5 & 14.9 & 0.390 \\
\multirow{3}{*}{ Cost (patient share, US dollars) } & Total & 21.8 & 21.0 & $<0.001 *$ \\
\multirow{4}{*}{ No. of complications } & Pure & 4594 & 3609 & $<0.001 *$ \\
& Total & 5099 & 3642 & $<0.001 *$ \\
& Pure & 1638 & 1180 & $<0.001 *$ \\
& Total & 1791 & 1209 & 0.184 \\
\hline
\end{tabular}

Endonasal, endoscopic endonasal reduction; Transcaruncular, transcaruncular reduction; No., number; EOM, extraocular movement limitation; Pure, pure medial orbital wall fracture.

$* p<0.05$, significant difference. 